\title{
Perfil dos trabalhadores de uma empresa do ramo têxtil e de confecção atendidos por um Centro de Referência em Saúde do Trabalhador do nordeste brasileiro
}

\author{
Workers' profile from a textile and clothing company attended by a Reference Center on \\ Occupational Health from the Brazilian Northeast
}

\author{
A. K. Da Silva ${ }^{1 *}$; J. L. F. Queiroz ${ }^{1}$; L. S. F. Rocha ${ }^{2}$; D. M. Gonçalves ${ }^{1}$; A. L. \\ Mafra $^{1}$
}

${ }^{I}$ Mestrado Profissional em Psicologia Organizacional e do Trabalho - MPPOT/Universidade Potiguar, CEP 59082902, Natal-RN, Brasil

${ }^{2}$ Discente da Graduação de Psicologia/Universidade Potiguar, CEP 59082-902, Natal-RN, Brasil

*aldakarolinel@yahoo.com.br

(Recebido em 29 de janeiro de 2018; aceito em 23 de abril de 2018)

\begin{abstract}
O campo da saúde do trabalhador assume práticas e conhecimentos que visa entender e intervir nas relações de trabalho e no processo saúde-doença, principalmente em uma sociedade que vive demasiadas mudanças econômicas, políticas e sociais. Assim, este artigo tem como objetivo descrever o perfil dos trabalhadores de uma empresa do ramo têxtil e de confecções atendidos em um Centro de Referência em saúde do Trabalhador (CEREST) do nordeste brasileiro e verificar se há prevalência de doenças nas ocupações estudadas. A pesquisa foi de caráter documental, em que foram analisados 268 prontuários abertos, de acesso restrito ao CEREST em questão. Os resultados apontaram que $85,4 \%$ são do sexo feminino e $14,5 \%$ são do sexo masculino, $45 \%$ chegaram ao serviço encaminhados pelo sindicato e $60,8 \%$ são da ocupação costureira. Para mulheres, foi visto que o teste Qui-quadrado apontou diferença na variação da incidência de doenças de acordo com a ocupação, tendo as doenças osteomusculares e do tecido conjuntivo como os acometimentos mais recorrentes. No entanto, não houve diferença na variação da incidência de doenças de acordo com a ocupação de homens. Também foi observado que $82,9 \%$ dos trabalhadores apresentam a sua capacidade laborativa comprometida e em $55,4 \%$ das CATs foram emitidas pelo sindicato. Os dados mostram que os novos tempos de revolução tecnológica, contraditoriamente, não produziram avanços significativos no campo da saúde do trabalhador, ainda vítima de um sistema fordista de produção e, por conseguinte, de adoecimento. Palavras-chave: CEREST, trabalhadores do ramo têxtil, adoecimento.
\end{abstract}

The field of worker health assumes practices and knowledge that seeks to understand and intervene in work relations and the health-disease process, especially in a society that lives too many economic, political and social changes. Thus, this article aims to describe the profile of a textile and clothing company workers who were attended in a Reference Center on Occupational Health (CEREST, accronym in Portuguese) from the Brazilian northeast and verify if there is prevalence of diseases in the studied occupations. The research was of a documentary nature, in which 268 medical records were analyzed, with restricted access to CEREST in question. The results indicated that $85.4 \%$ are female and $14.5 \%$ are male, $45 \%$ came to the service sent by the union, and $60.8 \%$ are seamstress. For women, the Chi-square test showed a difference in the incidence of diseases according to occupation, with osteomuscular and connective tissue diseases as the most frequent recurrences. However, there was no difference in the incidence of diseases according to the occupation of men. It was also observed that $82.9 \%$ of the workers had their work capacity compromised and the union issued 55.4\% of the CATs. The data show that the new times of technological revolution, contradictorily, did not produce significant advances in the field of worker health, still the victim of a Fordist system of production and, consequently, of illness.

Keywords: CEREST, textile workers, sickness. 


\section{INTRODUÇÃO}

A partir da década de 1980, o surgimento do campo da saúde do trabalhador permitiu o estreitamento da relação entre determinadas ocupações e o adoecimento psíquico, formulando o estudo das psicopatologias relacionadas ao trabalho [1]. No âmbito da saúde pública, até esse período o cuidado à população trabalhadora era responsabilidade das empresas e da previdência social, foi somente com a constituição de 1988 que a saúde (através da criação do Sistema Único de Saúde - SUS) e a saúde do trabalhador passaram a constituir um direito social [2]. Todavia, apenas em 2002, a Rede Nacional de Atenção Integral à Saúde do Trabalhador (RENAST) foi criada.

Para Dias e Hoefel (2005) [3], esta rede tem a finalidade de organizar e estruturar a práxis da Saúde do Trabalhador no SUS, nos diferentes níveis de atenção, sejam elas assistenciais, de vigilância ou de promoção à saúde. Ainda, a RENAST foi pautada no modelo de atenção do SUS, propondo, assim, uma atenção integral à Saúde do Trabalhador, com articulação intra e intersetoriais, apoio ao desenvolvimento de pesquisas, compartilhamento dessas informações, capacitação permanente e com participação da população na gestão das ações de saúde. Desta forma, a rede tem a atenção básica como porta de entrada e os Centros de Referência em Saúde do Trabalhador (CEREST) como serviço especializado e estratégico.

Quanto aos CERESTs, eles podem ser estaduais, com foco na educação em saúde, ou regionais, compreendendo ações de vigilância, assistência, prevenção de agravos, promoção da saúde e de informações em Saúde do Trabalhador [2]. O foco destes centros é o atendimento a trabalhadores formais, informais, autônomos, desempregados, estagiários e aposentados, desde que se estabeleça o nexo entre o adoecimento e o trabalho, com a atuação orientada, ou devendo ser orientada, na abordagem clínico-epidemiológica e de planejamento [3].

No entanto, mesmo após todos os estudos realizados desde o início do campo da saúde do trabalhador, estabelecer o nexo entre o adoecimento e a atividade de trabalho não é tarefa simples, sendo a elaboração do Nexo Técnico Epidemiológico Previdenciário (NTEP) uma grande conquista nesse campo [3][4]. A regulamentação previdenciária utilizada atualmente é baseada no Decreto $\mathrm{n}$. 6.042/2007, que altera o Decreto n. 3.048/1999. A principal mudança dessa alteração é que a relação entre o adoecimento e o ramo da atividade econômica deixa de ter um olhar individual (Nexo Técnico Previdenciário) e passa a ter uma perspectiva coletiva, baseada em estatísticas epidemiológicas [5].

Isto posto, os estudos epidemiológicos tornam-se umas das principais ferramentas aliadas ao campo da Saúde do Trabalhador, apontados por Cardoso (2015) [6] como uma estratégia de enfrentamento coletivo para ampliação da implantação do NTEP e, consequentemente, desenvolver normas de enfrentamento a degradação do trabalho. Nesse contexto, é necessário ter-se claro o conceito de Acidente do Trabalho, que consiste no evento ocorrido no exercício da atividade de trabalho ou em qualque situação em que o trabalhador esteja representando a empresa, provocando danos à saúde do trabalhador, morte, lesão corporal (pertubação funcional) ou comprometimento da capacidade laborativa (temporária ou permanente) [7]. Assim sendo classificam-se em três tipos: típico - cujo risco de acidente é considerado "inerente" a atividade de trabalho; doença ocupacional - quando as condições de trabalho, o conteúdo da atividade, etc., promovem o adoecimento; e acidente de trajeto - ocorrido quando o trabalhador está representando a empresa, ou seus intereses, ou no trajeto de sua residência para o trabalho e vive-versa [8].

Ao que se refere ao segmento da indústria têxtil, assim como os diversos setores da indústria, sempre esteve marcado pelo contingente populacional que emprega no território nacional, sendo caracterizado pelo processo de mudança, automatizando os sistemas de produção para dar conta da intensa competitividade [9]. Porém, há também a preocupação sobre a exposição destes trabalhadores aos riscos ergonômicos, sendo apresentados como os aspectos de risco mais críticos apontados pelos trabalhadores, por Comper e Padula (2013) [10], o desconforto ambiental, as posturas inadequadas e prolongadas, assim como ter que continuar o trabalho mesmo apresentando dor.

Toda essa expropriação do corpo, visível pela lógica da patologia laboral, aponta a existência de um "trabalho dominado". Nos termos de Seligmann-Silva (2011) [11], o desgaste atinge ao trabalhador aprisionando sua subjetividade. No desgaste há uma situação de trabalho dominado, 
fazendo com que o corpo e os potenciais psíquicos do trabalhador sejam consumidos pelo processo de trabalho e por constrangimentos a ele vinculados.

Deste modo, esta análise documental buscou descrever o perfil dos trabalhadores de uma empresa do ramo têxtil e de confecções atendidos em um CEREST do nordeste brasileiro e verificar se há diferença significativa na variação da incidência de doenças, isto é, se há prevalência de doenças de acordo com a ocupação. Cumprindo o compromisso com o Campo da Saúde do Trabalhador em produzir e sistematizar conhecimento dos agravos relacionados a saúde no trabalho, há a necessidade de problematização do contexto narrativo de desdobramento dos adoecimentos laborais.

\section{MÉTODOS}

Trata-se de um estudo descritivo, com dados secundários de origem documental, de uso restrito de um Centro de Referência em Saúde do Trabalhador (CEREST) da população de trabalhadores de uma empresa do ramo têxtil e de confecção atendidos do nordeste brasileiro cuja análise tratouse de 268 prontuários abertos neste serviço no período de 2010 a 2014. Foram excluídos da amostra os prontuários fora deste recorte temporal assim como de trabalhadores advindos de outra empresa.

Para tanto, inicialmente, realizou-se um estudo dos prontuários para conhecer sua estrutura e as informações disponíveis, os quais continham mais informações que as utilizadas no presente estudo. Para compilação e organização desses dados secundários, elaborou-se um formulário online contendo apenas as informações relevantes para o interesse da pesquisa. Este formulário foi compartilhado por meio de um endereço eletrônico, em que sua manipulação esteve disponível apenas entre os pesquisadores. A utilização deste recurso permitiu que os dados fossem sistematizados de forma segura e armazenados em um correio virtual criado exclusivamente para a pesquisa.

O formulário foi composto por 26 perguntas, semiabertas e fechadas, organizadas em três categorias: cinco questões referentes ao perfil socioprofessional; treze questões referentes à identificação do nexo causal e possíveis encaminhamentos; e oito questões referentes ao grau de comprometimento do agravo e sequelas. As variáveis sociais analisadas foram sexo e idade, além disso foram investigadas características relacionadas ao acidente de trabalho como o perfil de adoecimento relacionado ao trabalho, dados sobre afastamento, comprometimento da capacidade laborativa, entre outros. A ferramenta permitiu a extração imediata dos dados em planilha do Excel, o qual possibilitou a criação de um banco de dados e posterior análise.

Para verificar se há prevalência de uma ocupação para as doenças observadas nos prontuários do CEREST, foi feito um teste Qui-quadrado de Pearson para cada sexo devido ocupação e doenças relacionadas ao trabalho serem variáveis categóricas. Os dados foram rodados no programa Statistical Package for the Social Sciences (SPSS) 18, e o critério de significância adotado foi de p $<0,05$.

\section{RESULTADOS E DISCUSSÃO}

A análise documental totalizou 268 prontuários de trabalhadores atendidos no CEREST em questão. Destes, 229 são do sexo feminino representando $85,4 \%$ da amostra e 39 são do sexo masculino com uma porcentagem de $14,6 \%$ dos trabalhadores atendidos no CEREST. A média de idade foi de 38, 48 anos, (DP =9,00), apresentando como idades mínima de 20 anos e máxima de 64 anos. Nota-se que através da análise dos dados, é possível traçar o perfil dos trabalhadores atendidos no CEREST e a prevalência das doenças que acometem esses trabalhadores.

A tabela 1 apresenta como estes trabalhadores chegaram ao serviço. Dado relevante considerando a permanente busca de consolidação da atenção à Saúde do Trabalhador em promover a articulação com os demais serviços do SUS. 
Tabela 1: Origem do encaminhamento ao CEREST

\begin{tabular}{lll}
\hline Encaminhamento & Número & \% \\
\hline Sindicato & 121 & $45 \%$ \\
Demanda Espontânea & 28 & $10 \%$ \\
Amigos & 41 & $15 \%$ \\
INSS & 16 & $6 \%$ \\
Advogado & 3 & $1,5 \%$ \\
Não especificado & 15 & $6 \%$ \\
Serviços de saúde & 41 & $15 \%$ \\
Empresa & 3 & $1,5 \%$ \\
\hline
\end{tabular}

Assim, percebe-se que o Sindicato é o principal meio de encaminhamento ao serviço especializado, o que neste caso aponta uma articulação, mesmo que remediativa dessas instituições no campo da saúde do trabalhador. É essencial que os diversos modos de organizações coletivas dos trabalhadores sejam incitados à participação no campo da Saúde do Trabalhador, de tal modo que os sindicatos, conforme apontam Silva, Bernardo e Souza (2016) [12], sintam a necessidade real de incorporar as questões da saúde dos trabalhadores nas discussões e nas pautas. Segundo análises desses autores, dentre o conteúdo das cláusulas negociadas e reinvindicações a saúde dos trabalhadores não é prioridade, sendo, geralmente, as questões salariais e benefícios o foco das lutas sindicais.

Dentre as ocupações encontradas, foi possível identificar as funções que mais foram atendidas no CEREST no período analisado (tabela 2).

Tabela 2: Principais ocupações atendidas no CEREST

\begin{tabular}{lll}
\hline Ocupação & Número & \% \\
\hline Costureira & 163 & $60,8 \%$ \\
Auxiliar de produção & 55 & $20,5 \%$ \\
Operador de Máquina & 12 & $4,5 \%$ \\
Controlista de produção & 11 & $4,1 \%$ \\
Engomadeira & 6 & $2,2 \%$ \\
Situação de desemprego & 5 & $1,9 \%$ \\
Outros & 16 & $6,0 \%$ \\
\hline
\end{tabular}

Embora em baixa frequência, os trabalhadores apresentados na tabela 2 na condição de situação de desemprego justifica-se por seu vínculo anterior ser com a empresa estudada. Quanto à ocupação que mais procurou o serviço com queixas relacionadas ao trabalho, em primeiro lugar vem a de costureira. Mesmo com todas as mudanças tecnológicas, o padrão de adoecimento dessa categoria persiste com os velhos problemas [13]. Os novos tempos de revolução tecnológica, contraditoriamente, não produziu avanços no campo da saúde do trabalhador, ainda vítima de um sistema fordista de produção e, por conseguinte, de adoecimento. Outro dado de extrema releevância é a questão de gênero posta nessa atividade, esses(as) trabalhadores(as) são tipicamente mulheres, provedoras de suas famílias, cuja a capacidade laborativa vem sendo precocemente comprometida.

Os dados da previdência de 2014 mostraram que a atividade econômica de confecção de peças do vestuário, exceto roupas íntimas, apareceram entre as 20 atividades que mais adoeceram por dorsalgia, fratura na altura do punho e da mão, fratura da perna incluindo tornozelo, fratura de pé, fratura do antebraço, episódios depresivos, leiomyoma do últero, gravidez ectópica, e ferimento do 
punho e da mão [14]. Apesar destes dados não serem exclusivamente de adoecimentos relacionados ao trabalho, apresentam equivalência aos dados colhidos nesta pesquisa.

Levando em consideração a especificidade da história de vida e história de vida pelo trabalho de cada trabalhador, praticamente cada prontuário apresentava uma combinação de diagnóstico, dificultando uma leitura geral dos dados e consequente análise dos mesmos. Para facilitar a compreensão dos dados, a equipe de pesquisa optou por agrupar algumas patologias que apresentaram menor incidência e/ou características próximas, por exemplo, o Episódio depressivo e o Transtorno Misto Ansioso e depressivo, por apresentarem maior incidência, foram apresentados na tabela 3, já os demais transtornos psíquicos (Trantorno bipolar, Esquizofrenia, Transtorno de Personalidade, Transtorno de Adaptação, Reação aguda ao "stress") passaram a representar um mesmo grupo. No caso de dor: na mão, no cotovelo, no ombro, no joelho, no tornozelo, etc., passaram a compor um único grupo (dor nas articulações) pela variedade de partes do corpo acometidas.

As doenças e sintomas identificados nos prontuários estão apresentadas na tabela 3. Para mulheres, foi visto que o teste Qui-quadrado foi significativo $\left(\chi^{2}=129,74 ; p=0,001\right)$. Isto é, há diferença na variação da incidência de doenças de acordo com a ocupação de mulheres. No entanto, não houve diferença na variação da incidência de doenças de acordo com a ocupação de homens $\left(\chi^{2}=39,85 ; p=0,689\right)$. Isto é, para as mulheres, dentre as ocupações, houve maior prevalência de Sinovite e Tenossinotive e outros transtornos psíquicos em costureiras, Bursite/Tendinite, Dor Generalizada/Fibromialgia e Monoreuropatias foi mais incidente em engomadeiras; Dorsalgia/Lombalgia/Cervicalgia teve mais incidência em controlista de produção, dores nas articulações e Síndrome do Manguito Totator em auxiliaries de produção; Transtorno de Disco em controlista de produção, já as lesões em membros tiveram maior prevalência em operadores de máquina; o Transtorno Misto Ansioso e Depressivo de forma muito acentuada em desempregadas.

Um dado de extrema relevância é a questão de gênero posta nessa atividade, as quais são tipicamente mulheres, provedoras de suas famílias, cuja a capacidade laborativa vem sendo precocemente comprometida. Segundo Torres et al. (2011) [15] as mulheres estão mais vulneráveis ao acometimento de Lesões por Esforço Repetitivo (LER) e Disturbios Osteomuscular Relacionado ao Trabalho (DORT), não só pelas diferenças biológicas em relação aos homens, mas também por ainda exercerem uma dupla jornada, o trabalho externo as atividades dompesticas.

Chamamos a atenção para o grande número de doenças osteomusculares e do tecido conjuntivo, assim como transtornos psíquicos. Estes apontamentos coadinam com as estatísticas nacionais que apontam que doenças classificadas em $\mathrm{F}$ (grupo dos transtornos mentais e comportamentais) e $\mathrm{M}$ (grupo de doenças do sistema osteomuscular e do tecido conjuntivo). De acordo com a Classificação Internacional de Doenças (CID), juntas, as doenças classificadas em $\mathrm{F}$ e $\mathrm{M}$, representam 20,76\% dos afastamentos para benefício de Auxílio Doença [16].

Além de os resultados indicarem a persistência dos velhos tipos de adoecimento (relacionados as DORTS), como supracitado, alertam também para o agravamento das questões relacionadas à saúde mental. De acordo com Seligmann Silva et al. (2016) [11], as trabalhadoras desse setor produtivo são constante alvo de desgaste mental, seja pelo processo pericial em comprovar o adoecimento psíquico e sua relação com trabalho, ou pela dificuldade de readaptação ao mesmo, tendo muitas vezes que voltar a desenvolver a mesma função. Assim sendo, comumente é observado o desenvolvimento de quadros depressivos, de síndromes de ansiedade e/ ou pânico no processo de afastamento e retorno ao trabalho em trabalhadores que apresentam adoecimentos relacionados a LER. 
Tabela 3: Prevalência de doenças e sintomas relacionados ao trabalho por ocupação em mulheres

\begin{tabular}{|c|c|c|c|c|c|c|c|c|}
\hline \multirow{2}{*}{\multicolumn{2}{|c|}{$\begin{array}{l}\text { Doenças e sintomas relacionados ao } \\
\text { trabalho }\end{array}$}} & \multicolumn{7}{|c|}{ Ocupação } \\
\hline & & \multirow{2}{*}{$\frac{\text { Costureira }}{45}$} & \multirow{2}{*}{$\begin{array}{c}\begin{array}{c}\text { Auxiliar de } \\
\text { produção }\end{array} \\
8\end{array}$} & \multirow{2}{*}{$\begin{array}{c}\begin{array}{c}\text { Controlista de } \\
\text { produção }\end{array} \\
1\end{array}$} & \multirow{2}{*}{$\begin{array}{c}\text { Desempre- } \\
\text { gada } \\
0\end{array}$} & \multirow{2}{*}{$\begin{array}{c}\begin{array}{c}\text { Engoma- } \\
\text { deira }\end{array} \\
0\end{array}$} & \multirow{2}{*}{$\begin{array}{c}\begin{array}{c}\text { Operadora } \\
\text { de } \\
\text { máquina }\end{array} \\
0\end{array}$} & \multirow{2}{*}{$\frac{\text { Outra }}{1}$} \\
\hline Sinovite e & Freq. observada & & & & & & & \\
\hline Tenossinovite & Freq. esperada & 38.8 & 10.5 & 2.0 & 0.3 & 1.5 & 0.3 & 1.8 \\
\hline \multirow[t]{2}{*}{ Bursite/tendinite } & Freq. observada & 18 & 5 & 3 & 0 & 3 & 0 & 0 \\
\hline & Freq. esperada & 20.4 & 5.5 & 1.1 & 0.1 & 0.8 & 0.1 & 0.9 \\
\hline \multirow{2}{*}{$\begin{array}{l}\text { Dorsalgia/lombalg } \\
\text { ia/cervicalgia }\end{array}$} & Freq. observada & 9 & 2 & 1 & 0 & 0 & 0 & 0 \\
\hline & Freq. esperada & 8.5 & 2.3 & 0.4 & 0.1 & 0.3 & 0.1 & 0.4 \\
\hline \multirow{2}{*}{$\begin{array}{l}\text { Dor nas } \\
\text { articulações }\end{array}$} & Freq. observada & 18 & 6 & 1 & 0 & 0 & 0 & 0 \\
\hline & Freq. esperada & 17.6 & 4.8 & 0.9 & 0.1 & 0.7 & 0.1 & 0.8 \\
\hline \multirow{2}{*}{$\begin{array}{l}\text { Síndrome do túnel } \\
\text { do carpo }\end{array}$} & Freq. observada & 9 & 3 & 0 & 0 & 0 & 0 & 1 \\
\hline & Freq. esperada & 9.2 & 2.5 & 0.5 & 0.1 & 0.4 & 0.1 & 0.4 \\
\hline \multirow{2}{*}{$\begin{array}{l}\text { Transtorno de } \\
\text { disco }\end{array}$} & Freq. observada & 2 & 2 & 1 & 0 & 0 & 0 & 0 \\
\hline & Freq. esperada & 3.5 & 1.0 & .2 & .0 & 0.1 & .0 & 0.2 \\
\hline \multirow{2}{*}{$\begin{array}{l}\text { Lesões nos } \\
\text { membros }\end{array}$} & Freq. observada & 8 & 1 & 0 & 0 & 0 & 1 & 0 \\
\hline & Freq. esperada & 7.0 & 1.9 & 0.4 & .0 & 0.3 & .0 & .3 \\
\hline \multirow{2}{*}{$\begin{array}{l}\text { Episódio } \\
\text { depressivo }\end{array}$} & Freq. observada & 4 & 2 & 0 & 0 & 0 & 0 & 1 \\
\hline & Freq. esperada & 4.9 & 1.3 & 0.3 & .0 & 0.2 & .0 & 0.2 \\
\hline \multirow{3}{*}{$\begin{array}{l}\text { Transtorno misto } \\
\text { (ansioso e } \\
\text { depressivo) }\end{array}$} & Freq. observada & 6 & 1 & 0 & 1 & 0 & 0 & 1 \\
\hline & Freq. esperada & 6.3 & 1.7 & 0.3 & .0 & 0.2 & .0 & 0.3 \\
\hline & Freq. observada & 9 & 0 & 0 & 0 & 0 & 0 & 1 \\
\hline
\end{tabular}




\begin{tabular}{|c|c|c|c|c|c|c|c|c|}
\hline $\begin{array}{l}\text { Outros } \\
\text { transtornos } \\
\text { psíquicos }\end{array}$ & Freq. esperada & 7.0 & 1.9 & 0.4 & .0 & 0.3 & .0 & 0.3 \\
\hline \multirow{2}{*}{$\begin{array}{l}\text { Lumbago com } \\
\text { ciática }\end{array}$} & Freq. observada & 3 & 2 & 0 & 0 & 0 & 0 & 1 \\
\hline & Freq. esperada & 4.2 & 1.1 & 0.2 & .0 & 0.2 & .0 & 0.2 \\
\hline \multirow{2}{*}{$\begin{array}{l}\text { Dor } \\
\text { generalizada/mibr } \\
\text { omialgia }\end{array}$} & Freq. observada & 3 & 1 & 0 & 0 & 1 & 0 & 0 \\
\hline & Freq. esperada & 3.5 & 1.0 & 0.2 & .0 & 0.1 & .0 & 0.2 \\
\hline \multirow{2}{*}{$\begin{array}{l}\text { Síndrome do } \\
\text { manguito rotator }\end{array}$} & Freq. observada & 2 & $\mathbf{1}$ & 0 & 0 & 0 & 0 & 0 \\
\hline & Freq. esperada & 2.1 & 0.6 & 0.1 & .0 & 0.1 & .0 & 0.1 \\
\hline \multirow[t]{2}{*}{ Mononeuropatias } & Freq. observada & 1 & 1 & 0 & 0 & 2 & 0 & 0 \\
\hline & Freq. esperada & 2.8 & 0.8 & 0.1 & .0 & 0.1 & .0 & 0.1 \\
\hline \multirow[t]{2}{*}{ Outras patologias } & Freq. observada & 18 & 7 & 1 & 0 & 0 & 0 & 1 \\
\hline & Freq. esperada & 19.0 & 5.2 & 1.0 & 0.1 & 0.7 & 0.1 & 0.9 \\
\hline
\end{tabular}

Nota: Freq.: Frequência; ajust.: ajustado; Valores em negrito indicam prevalência de dença das ocupações. 
Outro fenômeno que pode ser observado são os acometimentos das pessoas em situação de desemprego ${ }^{1}$. Este foi o grupo que apresentou maior prevalência de Transtorno Misto Ansioso e Depressivo revelando o desgaste mental que a ausência de emprego pode gerar. Segundo Seligmann-Silva (2015) [17], mesmo que para alguns, de imediato, a demissão se apresente como um alívio, o passar dos dias e a recorrente dificuldade de encontrar novos trabalhos podem fazer com que o desgaste mental se agrave.

Ainda, podemos inferir que as patologias relacionadas às questões ergonômicas, exposição a materiais químicos e/ou biológicos e com riscos eminentes são as que estão mais em evidência no estabelecimento do nexo. Já as que envolvem as relações de trabalho e a forma como este é gerido apresentam mais dificuldades de serem diagnosticadas, problemática que precisa ser superada e amplamente discutida, para que esta não seja justificativa de omissões e/ou sub-notificaçoes no campo da ST.

Segundo Jardim et al. (2014) [4] para averiguar esses dois aspectos do adoecimento é preciso estar atento a duração do evento, não individualizar o processo de adoecimento, investigar a carga de trabalho, a pressão sofrida, se é uma atividade monótona, repetida, se o trabalhador tem controle sob a atividade, qual vínculo empregatício, as relações de apoio ou autoritarismo na organização, entre outros. Todo esse perfil de risco apontado é apresentado pelas trabalhadoras como presente em seu cotidiano de trabalho.

Além disso, chama atenção o número significante de prontuários (50) que não informavam a doença acometida pelo trabalhador, apresentadas na tabela no item 'não informado'. Vale salientar que o controle quanto ao preenchimento dos prontuários não estava sob a responsabilidade da equipe de pesquisa: estes são de uso interno do serviço e preenchidos pela própria equipe do CEREST. Esse número representa a real dficuldade do nexo causal, que precisa ser ponto de pauta e agenda nas dicussões dos atores envolvidos nesse processo.

$\mathrm{Na}$ investigação, verificamos o comprometimento da capacidade laborativa, dos 268 trabalhadores atendidos pelo serviço: 221 apresentam a sua capacidade laborativa comprometida $(82,9 \%)$ e $46(17,9 \%)$ não. Além de acabar acarretando em prejuízo econômico da empresa, a qual não conta com o trabalhado prestado e tem que arcar com os custos do afastamento, muitas vezes, esse comprometimento requer o afastamento do trabalhador da sua atividade profissional, podendo acarretar mais prejuízos a saúde do sujeito, pois o trabalho é visto como a atividade fundamental do ser humano para suprir suas necessidades básicas e de dignidade humana [8]. Assim, o sujeito fora do seu ambiente de trabalho poderá sofrer tanto as consequências sobre sua saúde, como as consequências financeiras e sociais que o afastamento de sua rotina de trabalho traz.

Deste modo, se faz necessário compreender os impactos na família gerados pelo adoecimento, estar atento a forma como a sociedade lida com o adoecimento, estar sensível a como o trabalhador vive esse processo de adoecimento e, mais ainda, compreender as dificuldades que esse trabalhador enfrenta na perícia do Instituto Nacional de Seguridade Social [7]. Outrossim, a partir da identificação do comprometimento da capacidade laborativa em um sujeito, pode-se iniciar uma reflexão sobre qual a melhor decisão a ser tomada para que ele continue desempenhando seu papel social de trabalhador.

Nessa perspectiva de valorização do sujeito, um dos caminhos a seguir seria a readaptação da função que ocasionou o adoecimento no trabalhador, salvo todas as dificuldades postas nesse processo. Embora a capacidade laborativa de um trabalhador possa oscilar ao longo de sua vida laboral, tanto no que diz respeito a qualidade quanto na quantidade, nem sempre o trabalhador acometido de agravo à saúde irá apresentar redução total e permanente de sua capacidade laborativa, mas frequentemente será afastado do seu ambiente de trabalho [18].

\footnotetext{
${ }^{1}$ Apesar da ausência de vínculo formal com a empresa, este grupo de trabalhadores permanecem relacionados a ela ou pela empresa ter sido o último vínculo empregatício ou o trabalhador foi demitido porque já estava adoecido e o CEREST precisa fazer esse registro para cumprir o papel de serviço de vigilância em saúde do trabalhador. Os prontuários não foram precisos ao fazer essa distinção.
} 
Quanto à readaptação, verificamos nos prontuários que apenas cinco $(1,9 \%)$ pacientes foram readaptados, enquanto que $146(55 \%)$ pacientes voltaram a exercer a mesma função após o tratamento do seu acometimento. Em $116(43,1 \%)$ prontuários, esta informação era ausente. Como aponta Atz (2016) [19], a readaptação de função, pode suceder uma diminuição do poder de ação dos sujeitos ao modo que os impede de continuar em seu ofício, podendo gerar sofrimento psíquico ao trabalhador, independente se a readaptação da função é do seu desejo ou é algo imposto. Por outro lado, ela também pode resultar em um novo contexto de existência, abrindo possibilidades para o trabalhador encontrar outro meio de existir a partir de uma nova atribuição.

A tabela 4 mostra aque em 30,2\% dos prontuários informaram que a CAT não foi emitida, e $8,6 \%$ não apresentavam essa informação.

Tabela 4: Emissão de CAT

\begin{tabular}{lll}
\hline CAT emitida por & Número & $\%$ \\
\hline Empresa & 10 & $3,7 \%$ \\
Sindicato & 148 & $55,2 \%$ \\
Não emitida & 81 & $30,2 \%$ \\
Não informado & 23 & $8,6 \%$ \\
INSS & 3 & $1,1 \%$ \\
Usuário & 1 & $0,4 \%$ \\
CEREST & 2 & $0,7 \%$ \\
\hline
\end{tabular}

Os prontuários analisados apresentaram uma realidade um pouco distante do que se espera quanto ao reconhecimento da importância da emissão deste documento para garantias ao trabalhador e construção de dados estatísticos reais sobre as condições de trabalhado no cenário nacional. Considerando que no Brasil a emissão da CAT é exigida em caso de trabalhador dito "celetista", estando confirmado o NTEP, assim este é um instrumento oficial de comunicação no âmbito da Previdência Social [20].

A importância da emissão deste documento deve-se aos fatos de sê-lo intrumento para argumento legal na busca de manutenção de direitos trabalhistas dos acidentados, assim como para alimentar dados estatísticos que servirão de embasamento para ações de políticas públicas no âmbito da Saúde do Trabalhador [21].

Ademais, a subnotificação de trabalhadores acidentados provenientes do mercado fomal é apenas uma parcela da problemática que gira em torno de dados reais sobre acidentes de trabalho no cenário brasileiro, porquanto ficam de fora destas estatísticas os trabalhadores informais, autônomos, etc. por não existir outro sistema de informação que os inclua [20]. Essa subnotificação é um nó nos termos de Dias e Hoefel (2015) [3], no campo da saúde do trabalhador, cuja fomentação de suas políticas sofrem interferência quanto aos recursos materias e humanos destinados a área.

No geral, ainda temos muito o que avançar quando o assunto é o comprometimento da capacidade para o trabalho, seja ela definitiva ou temporária, pois, o que temos visto no Brasil enquanto ações das políticas públicas são preocupações apenas quanto aos números de acidentes registrados por meio de Comunicação de Acidente de Trabalho (CAT) e a avaliação dos gastos previdênciários [22].

\section{CONCLUSÃO}

Ainda temos um cenário produtivo extremamente pautado nas relações de poder e subserviência. Todo aparato tecnológico desta Era não foi suficiente para evitar o adoecimento do corpo do trabalho, ademais há um desgaste do corpo e principalmente da mente, ao ponto de enlouquecer, nos termos de Dejuors (2015) [23], devido ao trabalho. A violência nos espaços de trabalho é fortemente cercada pelas questões de gênero. Nosso público foi tipicamente feminino e de uma 
classe social de extrema vulnerabilidade, características que tradicionamente as fazem permecer em uma postura de subserviência e extrativismo.

Isto posto, os resultados desta pesquisa apresentam-se como um alerta às políticas públicas de saúde do trabalhado no que tange a proteção, assistência e prevenção destes casos, políticas estas que se apresentam de forma tão fragilizadas sendo uma das grandes limitações e dificuldades no campo da saúde do trabalhador. No estado em que se realizou a pesquisa tem o ramo têxtil como um setor produtivo importante para economia, o qual não se pode eximir o cuidado protetivo e curativo desses trabalhadores. Ademais, as instâncias regulamentadoras devem estar articuladas, por conseguinte, à atuação em parceria dos CEREST com instituições sindicais, ministério público do trabalho apresenta-se como uma via de fomento e implantação de ações no campo da saúde do trabalhador mais propositivas e contextualizadas ao cenário local.

Pesquisas como esta são de grande importância para a produção de informações no campo de saúde do trabalhador, de maneira que as reflexões aqui apresentadas lancem um olhar para o cenário atual e permita o aprofundamento de discussões por vezes negligenciadas. Diante disso, a análise da exposição aos fatores de risco ergonômicos auxilia o planejamento de estratégias que contribuam para a melhoria das condições de trabalho e, consequentemente, para a redução dos distúrbios osteomusculares nesses trabalhadores, típicos nessa categoria. No entanto, ficamos restritos a apenas uma categoria, não sendo possível comparar as mulheres do setor têxtil com outras em situações consideradas de menor vulnerabilidade e com homens em ambas as situações. Tal questão deve ser abordada em futuros estudos, assim como o destaque para a incidência dos transtornos psíquicos. Esses dados geralmente são velados e individualizados, relacionados a uma concepção segregada e psicopatologizante de sujeito-trabalhador.

Além disso, embora os dados utilizados tenham sido provenientes do período de 2010 a 2014, eles foram analisados conjuntamente, o que não possibilitou traçar uma perspectiva cronológica quanto à saúde dos trabalhadores objetos do estudo. Uma pesquisa longitudinal possibilitaria investigar como a saúde desses trabalhadores vem sido afetada ano após ano.

Com base nos achados do estudo atual verificamos que precisamos ampliar as redes de cuidado, não somente daquele que está adoecido (trabalhadora-costureira), mas as condições do que a faz adoecer (os modos de desenvolvimento e gestão da sua atividade de trabalho). Ser costureira em si não é algo adoecedor, mas o modo como as costureiras são gestionadas pode ser um fator de risco no processo saúde-doença. Dispomos de diversos recursos no campo da saúde e segurança do trabalho que postos em ação podem abrandar os índices de asfastamentos pelos problemas físicos, acrescido a isto temos a associação real das doenças físicas ao desenvolvimento de problemas psíquicos, os quais devem ser alvo de estudo mais ampliados no ambito da relação saúde-trabalho.

\section{REFERÊNCIAS BIBLIOGRÁFICAS}

1. Silva CO, Ramminger T. O trabalho como operador de saúde. Ciênc. saúde coletiva. 2014;19(12):47514758, doi:10.1590/1413-812320141912.15212013

2. Brasil. Portaria $n^{\circ} 1.823$, de 23 de junho de 2012. Institui a Política Nacional de Saúde do Trabalhador e da Trabalhadora. Política Nacional de Saúde do Trabalhador e da Trabalhadora. Brasília; 2012.

3. Dias EC, Hoefel MG. O desafio de implementar as ações de saúde do trabalhador no SUS: a estratégia da RENAST. Ciênc. saúde coletiva. 2005 Dec;10(4):817-827. Available from. access on 14 July 2015. doi:10.1590/S1413-81232005000400007.

4. Jardim SR, et al. Diagnóstico e nexo com o trabalho. In Glina DMR, Rocha LE, orgs. Saúde mental no trabalho: Da teoria à prática. São Paulo: Roca; 2004. p. 49-80.

5. Dallegrave Neto JA. Nexo Técnico Epidemiológico e seus efeitos sobre a Ação Trabalhista Idenizatória. Rev. Trib. Reg. Trab. 3 Reg. 2007 Jul/Dez;46(76):143-153.

6. Cardoso ACM. O trabalho como determinante do processo saúde-doença. Tempo Social. Rev. Sociol. USP. 2015 Jun;27(1):73-94.

7. Brasil. Ministério da Saúde (MS). Secretaria de atenção à saúde. Notificação de Acidentes do Trabalho Fatais, Graves, e com Crianças e Adolescentes. Brasília: MS; 2006.

8. Bandeira N, et al. Subjetividade e acidente de trabalho no contexto contemporâneo. Psicol. Am. 2008. Lat., México, n.

15 , dez.

Disponível

em 
$<$ http://pepsic.bvsalud.org/scielo.php?script=sci_arttext\&pid=S1870350X2008000400006\&lng=pt\&nrm=iso >.

9. Braga Jr E, et al. O Processo de Transferência de Tecnologia na Industria têxtil. JOTMI. 2009;4(1):125133, doi:10.4067/S0718-27242009000100011

10. Comper MLC, Padula RS. Avaliação do risco ergonômico em trabalhadores da indústria têxtil por dois instrumentos: quick exposure check e job factors questionnaire. Fisioter Pesq. 2013;20(3):215-221, doi:10.1590/S1809-29502013000300004

11. Seligmann-Silva E. Trabalho e desgaste mental: o direito de ser dono de si mesmo. São Paulo: UFRJ/Cortez; 2011.

12. Silva MP, et al. Relação entre saúde mental e trabalho: a concepção de sindicalistas e possíveis formas de enfrentamento. Rev. bras. Saúde ocup. 2016;41,e23, doi:10.1590/2317-6369000003416

13. Sato L, et al. Psicologia e saúde do trabalhador: práticas e investigações na Saúde Pública de São Paulo. Estud. psicol. (Natal). 2006;11(3):281-288, doi:10.1590/S1413-294X2006000300005

14. Brasil, Ministério da Fazenda. Uma análise das doenças que mais geraram benefícios por incapacidade para os segurados da Previdência Social no ano de 2014. $2^{\mathrm{a}}$ Boletim Quadrimestral sobre Benefício por Incapacidade. Brasília; 2016.

15. Torres ARA, et al. O adoecimento no trabalho: repercussões na vida do trabalhador e de sua família. S A N A R E. 2011 Jan/Jun;10(1):42-48.

16. Brasil. Ministério da Previdência Social. Informe Especial por Ocasião do Dia Mundial em Homenagem às Vítimas de Acidente do Trabalho. $1^{\mathrm{a}}$ Boletim Quadrimestral sobre Benefício por Incapacidade Brasília; 2014.

17. Seligmann-Silva E. Desemprego e Desgaste mental: Desafio às políticas públicas e aos sindicatos. RCT. 2015;4:89-109.

18. Corsatto RF. Análise Da Readequação Laboral De Taquígrafos Com Base Nos Princípios Da Psicodinâmica Do Trabalho. 2013. 21 F. Trabalho De Conclusão De Curso (Especialização Em Psicodinâmica Do Trabalho) - Universidade De Brasília, Brasília, Http://Bdm.Unb.Br/Handle/10483/8398

19. Atz MV. Reflexões Sobre Trabalho E Reabilitação Profissional: Experiências Em Estágios. Porto Alegre; 2016 P. 8-13. http://www.lume.ufrgs.br/bitstream/handle/10183/148291/001002620.pdf?sequence=1

20. Cordeiro R, et al. O sistema de vigilância de acidentes do trabalho de Piracicaba, São Paulo, Brasil. Cad. Saúde Pública. 2005 Oct;21(5):1574-1583, doi:10.1590/S0102-311X2005000500031.

21. Bernardo MH, Garbin A. A atenção à saúde mental relacionada ao trabalho no SUS: desafios e possibilidades. Rev. bras. Saúde ocup. 2011 Jan/jun36(123).

22. Silva ABRB. Acidentes, adoecimento e morte no trabalho como tema de estudo da História. In: Oliveira TB, org. Trabalho e trabalhadores no Nordeste: análises e perspectivas de pesquisas históricas em Alagoas, Pernambuco e Paraíba. EDUEPB. 2015, p. 215-240. ISBN 978-85-7879-333-3.

23. Dejours C. A loucura do trabalho: estudo de psicopatologia do trabalho. 6nd ed. São Paulo: Cortez; 2015. $224 \mathrm{p}$. 